\title{
Evaluation of quality characteristics of composite cake prepared from mixed jackfruit seed flour and wheat flour
}

\author{
S. A. Khan, M. N. Saqib* and M. A. Alim \\ Department of Food Technology and Rural Industries, Bangladesh Agricultural University, Mymensingh-2202, \\ Bangladesh, *E-mail: saqib.fe@gmail.com
}

\begin{abstract}
In this study, attempt was taken to increase the functionality of cake by substituting wheat flour with $10 \%, 20 \%$, and $30 \%$ jackfruit seed flour (JSF). JSF contained $6.29 \%$ moisture, $13.23 \%$ protein, $3.09 \%$ crude fibre, $73.42 \%$ carbohydrates, $2.72 \%$ ash and $1.25 \%$ fat, and wheat flour contained $12.86 \%$ moisture, $1.2 \%$ ash, $10.76 \%$ protein, $1.32 \%$ fat, $1.4 \%$ crude fibre and $72.46 \%$ carbohydrate. Three cake samples were prepared with composite flour (JSF and wheat flour)mixed with other ingredients and compared with a control sample. The specific volume of cake for $20 \%$ substitution was higher than that of all other cakes. The crust and the crumb characteristics changed with the incorporation of JSF. Proximate composition of the cakes like carbohydrate, ash, fibre and protein increased with the substitution of JSF, butfat and protein decreased. Nutritionally, composite cakes with different levels of JSF were found better than control sample. In sensory tests, significant changes were found in color, flavour, texture and taste, and overall acceptability of cakes were observed with the increase of substitution. However, cake with $10 \%$ JSF incorporation got the highest acceptability by the panelists.
\end{abstract}

Keywords: Jackfruit seed flour, Cake, Quality

\section{Introduction}

Now a day, bakery products have drawn the attention of scientists for their wider application as functional food because of having a scope for substituting root, tuber, leaf, legume, etc. as a potential alternative to wheat flour. Demand for bakery products is increasing at the rate of $10.07 \%$ per annum (Kamaljit et al., 2010). Many innovations have already been seen in bakeries for adding value to their products. Breads and cakes with herbal incorporation like carrot pomace are available in the market (Upadhyay et al., 2008; Vassallo et al., 2009). Singh et al. (2006) described Pearl millet incorporation in cake or even the herb shatavari (Asparagus racemosus) was utilized (Singh et al., 2014). These substitutions result in a significant change to the nutritional and qualitative properties of finished products, specially the fiber content, which directly influencesthe functional properties like increased water holding, gel forming, stabilizing, texturizing and thickening capacities (Kunzek et al., 2002;Dikeman et al., 2006).

Jackfruit (Artocarpus heterophyllus), a member of the family Moraceae, is a popular fruit of the tropics. It grows widely and abundantly in India, Bangladesh (Rahman et al., 1999), South-East Asia and in the evergreen forest zone of West Africa (Burkil, 1997). The fruit consists of edible bulbs of yellow-flesh, rind and seeds. It is either eaten directly or processed to chips and snacks for later consumption.

Seeds make up around 10 to $15 \%$ of the total fruit weight (30-365/fruit) and have high carbohydrate and protein contents (Ocloo et al., 2010). People in the subcontinent eat this seed at boiled or roasted state. As the seed readily germinates, it is difficult to store it with present storage facilities in many under developed countries. As a result, a huge amount of jackfruit seed is wasted without consuming. But the seeds could be easily blended with traditional wheat flour to prepare more nutritious bakery items like breads, cakes, etc.

Wheat flour is one of the main ingredients of baking industry. But, the price of it is increasing daily for its multipurpose use in baking industry. Hence, replacing jackfruit seed flour with wheat flour will make a composite effect on nutritional and flavour aspects of bakery products. Again, as the jackfruit is cheap, it will ensure a low cost product for the lower incoming people. Cake is one of the palatable and popular bakery products for all ages. So, if we prepare cake with mixed flour that includes wheat flour and jackfruit seed flour, it will serve nutrition for all ages.

With this view, the purpose of this study is to evaluate the quality (physic-chemical and organoleptic) of composite cake prepared by adding different levels of JSF by replacing wheat flour. 


\section{Materials and Methods}

This study was conducted at the laboratory of the Department of Food Technology and Rural Industries under the Faculty of Agricultural Engineering and Technology, Bangladesh Agricultural University, Mymensingh.

Commercial whole meal wheat flour of "teer" a brand of city group (12-13\% moisture) collected from local market was used for making cake. Jackfruit seeds were collected from jackfruit which was bought from local market. The collected seeds were cleaned, peeled and dried.

\section{Chemicals, solvents and ingredients}

Chemicals and solvents used in the study were of AR grade, and water was glass distilled unless specified otherwise. Sugar, salt, soya bean oil, baking powder and egg were procured from the local market. High density polythene bags were used for packaging and storage of samples. Other minor ingredients were used from laboratory stocks.

Preparation of jackfruit seed flour: After collection of jackfruit, the seeds were separated from the arils manually. Then, the seeds were sorted and washed, and used for further processing. The process of preparing JSF with spermoderm is shown schematically in Fig. 1.

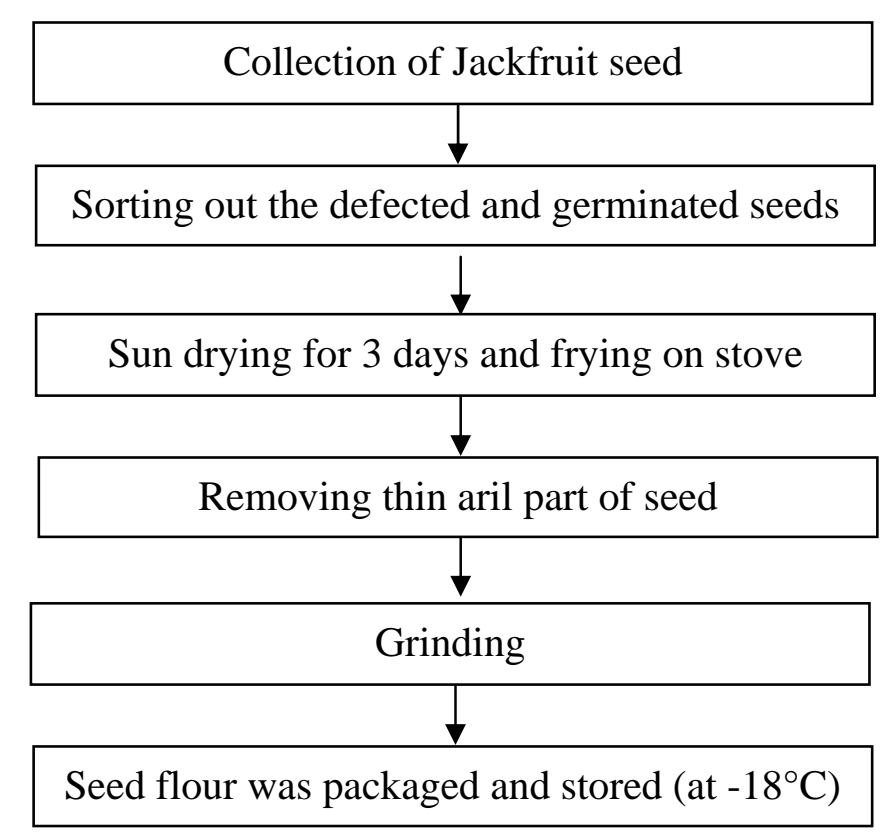

Fig. 1. Schematic diagram showing sequence of preparation of jackfruit seed flour

Preparation of cake: cakes were prepared by replacing wheat flour with different levels of jackfruit seed flour in the basic formulation of cake (Table 1) as per the methods of Rajchel et al. (1975). The wheat flour, jackfruit seed flour and other ingredients for each cake were weighed accurately, and the sugar and shortening were mixed in a mixing machine for 20 minutes to produce a cream. In later stages, oil, egg and other ingredients and, finally, the flour were mixed using a mixer at low speed (145 rpm) for 10 minutes to ensure even distribution of the components. The bowl was scrapped and batter was mixed for an additional two minutes at medium speed $(250 \mathrm{rpm})$. After the bowl was scrapped, the batter was mixed for an additional two minutes at medium speed. Portion of batter, weighing $150 \mathrm{~g}$, was scaled into pregreased cake pan. All cakes were baked in convection oven for 40 minutes at $170^{\circ} \mathrm{C}$. 
Table 1. Formulation of composite cake

\begin{tabular}{l|cc|c|c}
\hline \multirow{2}{*}{\multicolumn{1}{c}{ Ingredients }} & \multicolumn{5}{c}{ Quantity (g) } \\
\cline { 2 - 5 } & ${ }^{*} \mathbf{S}_{\mathbf{1}}$ & $\mathbf{S}_{\mathbf{2}}$ & $\mathbf{S}_{\mathbf{3}}$ & $\mathbf{S}_{\mathbf{4}}$ \\
\hline Powdered sugar & 70 & 70 & 70 & 70 \\
Soybean oil & 40 & 40 & 40 & 40 \\
Baking powder & 3.5 & 3.5 & 3.5 & 3.5 \\
Egg & 50 & 50 & 50 & 50 \\
Wheat flour & 100 & 90 & 80 & 70 \\
Jackfruit seed flour & 0 & 10 & 20 & 30 \\
\hline
\end{tabular}

${ }^{*} S_{1}=$ Control cake (with only wheat flour), $S_{2}=10 \%$ JSF containing cake, $S_{3}=20 \%$, JSF containing cake, $S_{4}=30 \%$ JSF containing cake

\section{Chemical Analysis}

The jackfruit seed flour and cake prepared by incorporation of jackfruit seed flour were analyzed for moisture, ash, protein, fat, crude fibre and carbohydrate contents. The moisture and fibre contents were determined as per the methods described by AOAC (2012)and ash, protein and fat were determined following the methods described by Ranganna (2005). The carbohydrate content was determined by difference, that is, by subtracting the measured moisture, ash, protein and fat content from 100 (Pearson, 1976).

\section{Sensory evaluation of cake}

The symmetry and the characteristics of crust and crumb of the cakes supplemented with jackfruit seed flour were evaluated and recorded. Cakes were evaluated organoleptically for colour, flavour, texture and overall acceptability. A 1-9 point hedonic rating test was also performed to assess the degree of acceptability of cakes containing jackfruit seed flour. A set of 20 panelists was selected from teacher, students and employee of the Department of Food Technology and Rural Industries, Bangladesh Agricultural University and briefed on procedure before evaluation. One slice from each lot of cake was presented to 20 panelists as randomly coded samples. The taste panelists were asked to rate the sample for colour, flavour, texture and overall acceptability on a $1-9$ point scale, where 1 = dislike extremely; $2=$ dislike very much; $3=$ dislike moderately; $4=$ dislike slightly; $5=$ neither like nor dislike; $6=$ like slightly; $7=$ like moderately; 8 =like very much; 9 = like extremely.

\section{Statistical analysis}

The results were evaluated by Analysis of variance and Duncan's New Multiple Range Test procedures using statistical software Statistical Analysis System (SAS, 1985).

\section{Results and Discussion}

\section{Composition of wheat flour and JSF}

The analysis of wheat flour and JSF gave the proximate composition and the results obtained are presented in Table 2. The wheat flower contained $12.86 \%$ moisture, $10.76 \%$ protein and $72.46 \%$ total carbohydrate content, respectively. The composition of wheat flour under study was near about Mollik (2006), who reported the nutrient content of wheat flour as follows: moisture $13.63 \%$, ash $1.15 \%$, protein $11.44 \%$, fat $0.88 \%$, and total carbohydrate $72.9 \%$. The moisture, protein and total carbohydrate content of JSF were $6.29 \%, 13.23 \%$ and $73.42 \%$, respectively. These results were similar with the results obtained by Ocloo et al. (2010) who found $6.09 \%$ moisture, $79.34 \%$ carbohydrate, $13.50 \%$ protein, $1.27 \%$ fat, $3.19 \%$ crude fiber and $2.70 \%$ ash in jackfruit seed powder. The differences observed in these compositions may be due to varietal differences, agro-ecological condition, fertilizer use, methods of analysis etc. 
Table 2. Composition of wheat flour and jackfruit seed flour (JSF)

\begin{tabular}{l|c|c}
\hline Components & Wheat flour (\%) & Jackfruit seed flour (\%) \\
\hline Moisture & 12.86 & 6.29 \\
Ash & 1.20 & 2.72 \\
Protein & 10.76 & 13.23 \\
Fat & 1.32 & 1.25 \\
Crude fibre & 1.4 & 3.09 \\
Total carbohydrate (by difference) & 72.46 & 73.42 \\
\hline
\end{tabular}

\section{Physical properties of cake}

\section{Specific volume}

The volume of a cake is the most important physical quality parameter used for the evaluation of a cake. It is a quantitative measurement and correlates well with dough handling properties, crumb, texture, freshness and technological versatility (Pomeranz, 1980).As illustrated in Fig. 2, 20\% jackfruit seed flour in cake formulations gave higher cake volume than those of $10 \%$ and $30 \%$ of jackfruit seed flour incorporation. This may occur due to absorbing air, oil and fibre components, which lead to enhancement of cake volume.

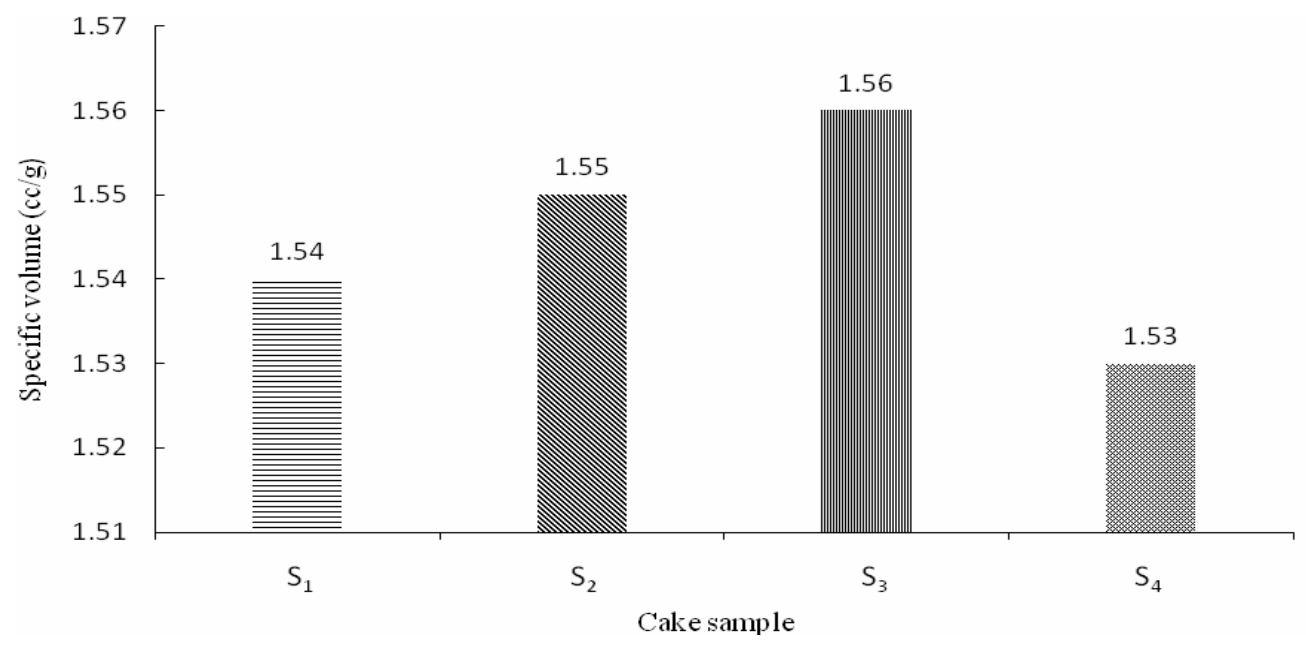

Fig. 2. Specific volume of different cake samples

\section{Crust and crumb characteristics}

Incorporation of jackfruit seed flour has shown some significant impacts on crust and crumb characteristics. The results are given in Table 3. The crust and crumb characteristic of a cake depend on the physical and chemical reactions during baking process. The heating mood and airflow also have impact on physical characteristics. Incorporation of jackfruit seed flour makes the composition of cake different compared to plain control cake and thus put a noticeable change to its physical properties.

Table 3. Crust and crumb characteristics of cake

\begin{tabular}{|c|c|c|c|c|c|c|c|}
\hline \multirow{3}{*}{ Sample } & \multicolumn{2}{|c|}{ Crust characteristics } & \multicolumn{5}{|c|}{ Crumb characteristics } \\
\hline & \multirow[b]{2}{*}{ Color } & \multirow[b]{2}{*}{ Consistency } & \multirow[b]{2}{*}{ Color } & \multicolumn{2}{|c|}{ Texture } & \multirow[t]{2}{*}{ Odor } & \multirow[b]{2}{*}{ Air cell } \\
\hline & & & & $\begin{array}{l}\text { Lumps and } \\
\text { hardness }\end{array}$ & Surface & & \\
\hline${ }^{*} S_{1}$ & Light brown & Tender & Yellow & Slightly free & Smooth, silky & Appetizing & Less airy \\
\hline $\mathrm{S}_{2}$ & Brownish & Medium tender & Light yellow & Slightly free & Smooth & Appetizing & Close \\
\hline $\mathrm{S}_{3}$ & Deep brown & Medium tough & White yellow & Free & Light smooth & Slightly fresh & Close \\
\hline $\mathrm{S}_{4}$ & Deep brown & Medium tough & White yellow & Present & Rough & Sweet & Close \\
\hline
\end{tabular}

${ }^{*} S_{1}=$ Control cake (with only wheat flour), $S_{2}=10 \%$ JSF containing cake, $S_{3}=20 \%$, JSF containing cake, $S_{4}=30 \%$ JSF containing cake 


\section{Chemical composition of cake}

The change of moisture content of cakes is illustrated in Fig. 3 . The moisture decreased from sample $S_{1}$ to $S_{4}$ due to the lower moisture content of jackfruit seed flour. The protein contents of the cake, containing jackfruit seed flour, are presented in Fig 4. It is observed that protein content in jackfruit seed flour cake samples increased (from $S_{2}$ to $S_{4}$ ) with increased substitution level of jackfruit seed flour in dough. This is due to presence of higher protein content in Jackfruit seed flour.

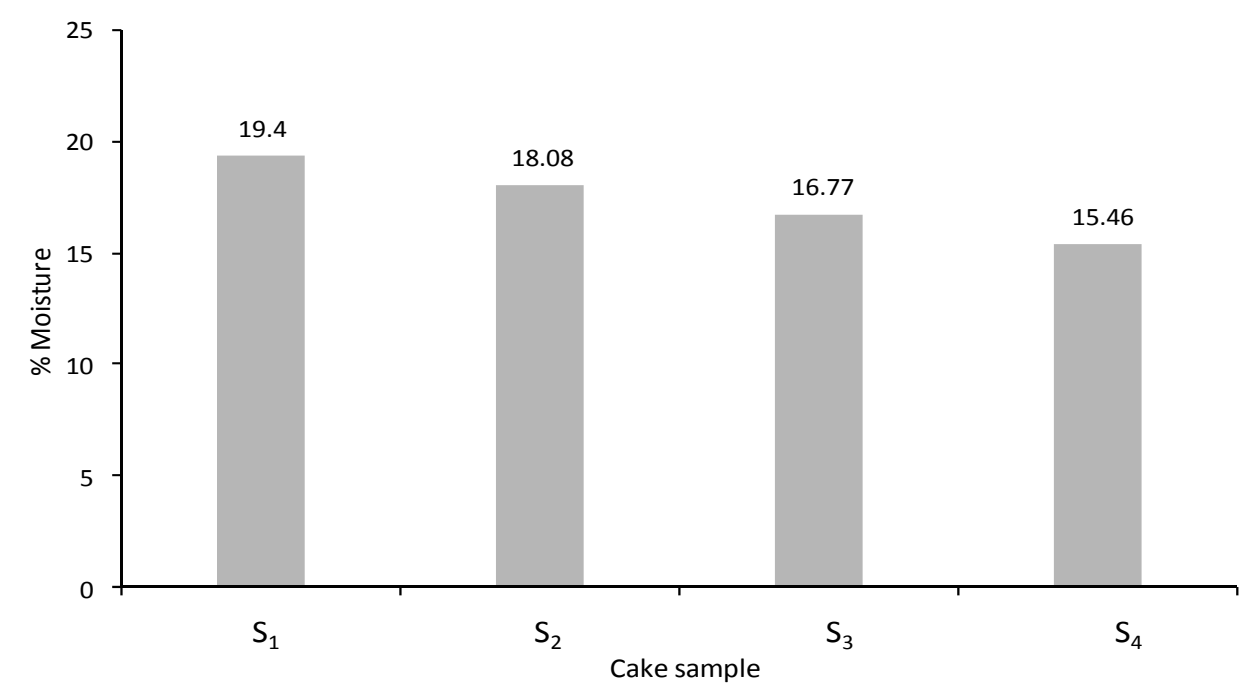

Fig. 3. Moisture contents of different cake samples

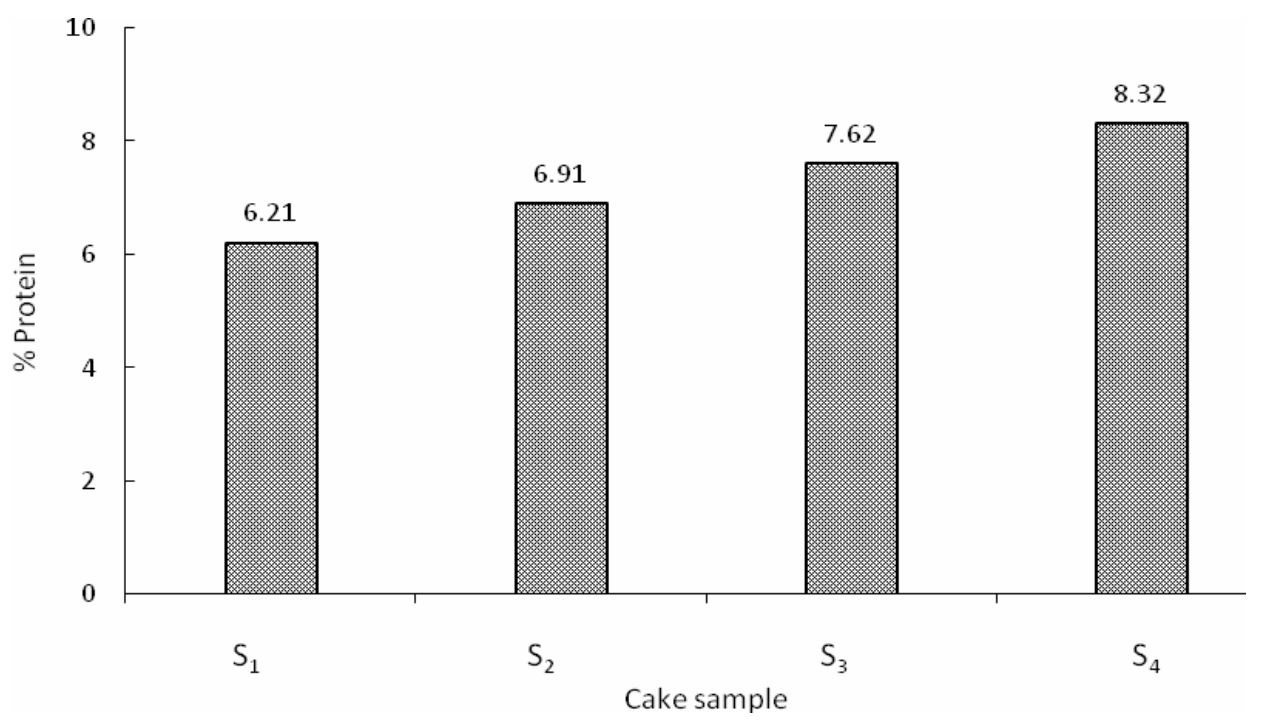

Fig. 4. Protein contents of different cake samples

As shown in Fig. 5, the fat contents of cake samples decreased with increasing the percentage of jackfruit seed flour in batter. Amin (2009) used jackfruit seed flour in cake samples and observed in cakes substituted with jackfruit seed flour, that fat content decreased compared to control cake.

The ash content of different cake samples increased with increased jackfruit seed flour substitution levels (Fig. 6). This might be due to the fact that jackfruit seed flour contains higher amount of ash than wheat flour. 


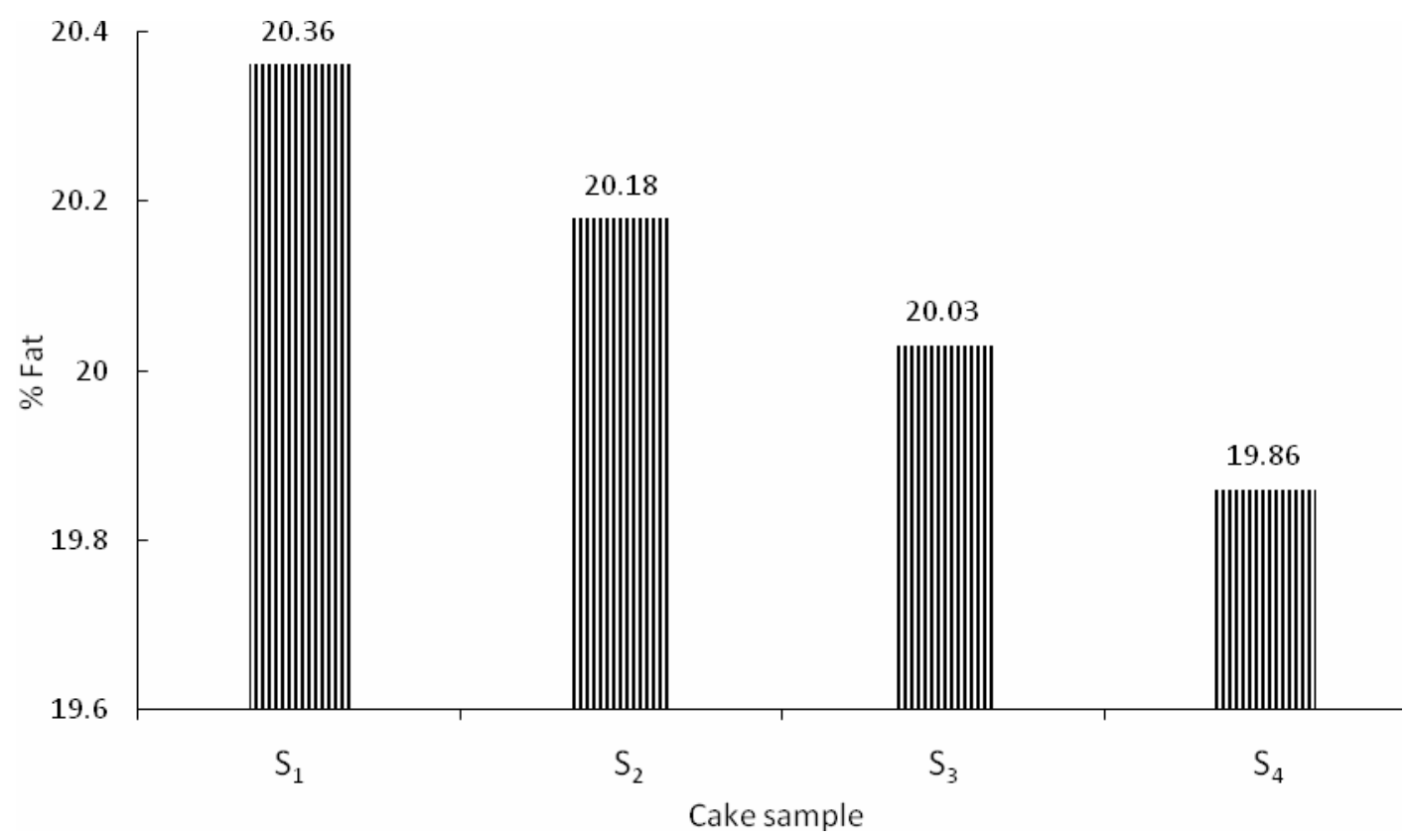

Fig. 5. Fat contents of different cake samples

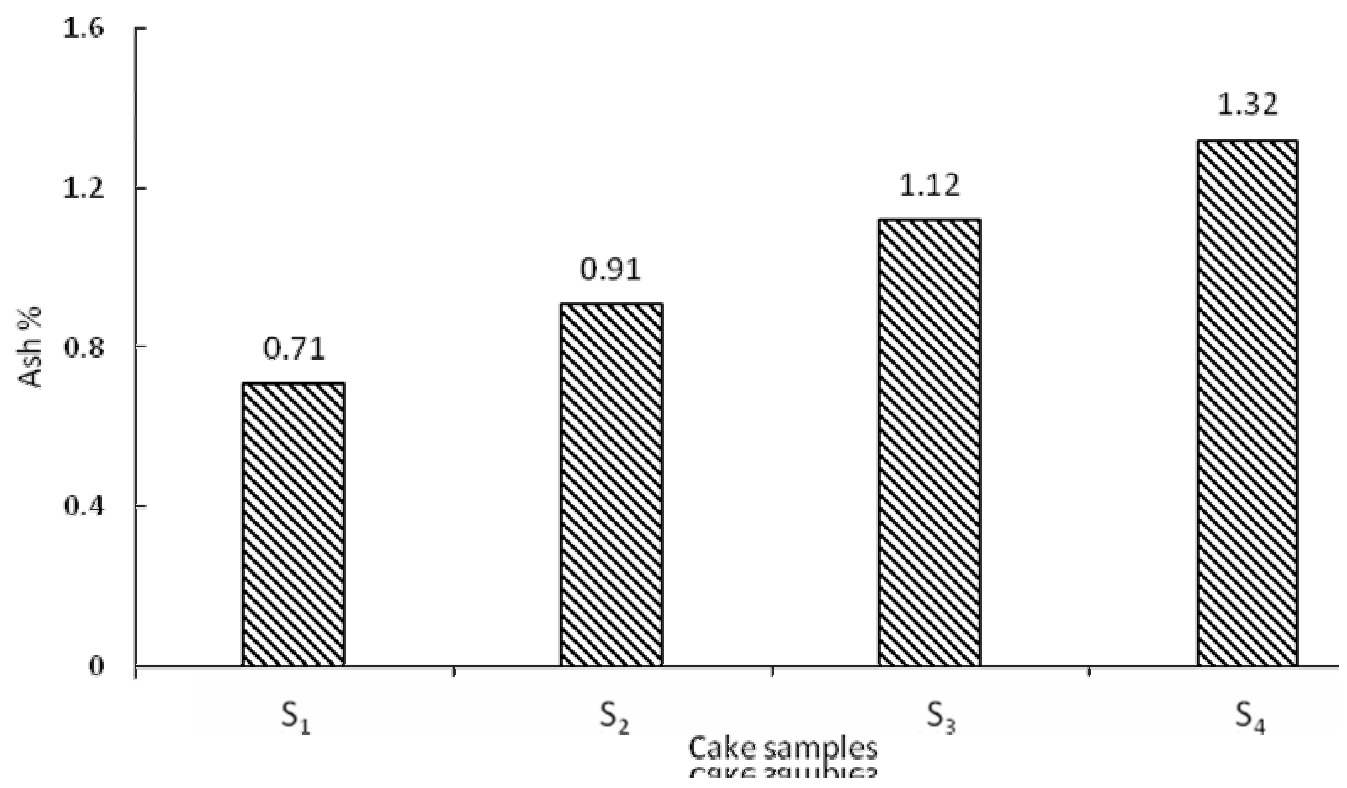

Fig. 6. Ash contents of different cake samples

Fig. 7 illustrates that crude fiber contents of the cakes, containing jackfruit seed flour were significantly higher than that of the control cake. The highest fiber content (1.27\%) was obtained in the cake $\mathrm{S}_{4}$ and the lowest fiber content was obtained in cake $S_{1}(0.49 \%)$. The fiber content $(1.27 \%)$ of the cake $S_{4}$ was much higher than those reported by Leung et al. (1972) who found $0.2 \%$ fiber in plain cake.

The variations in the carbohydrate content among cake samples under study (Fig. 8) might have resulted from the difference in the level of protein, fat, ash and moisture content. 


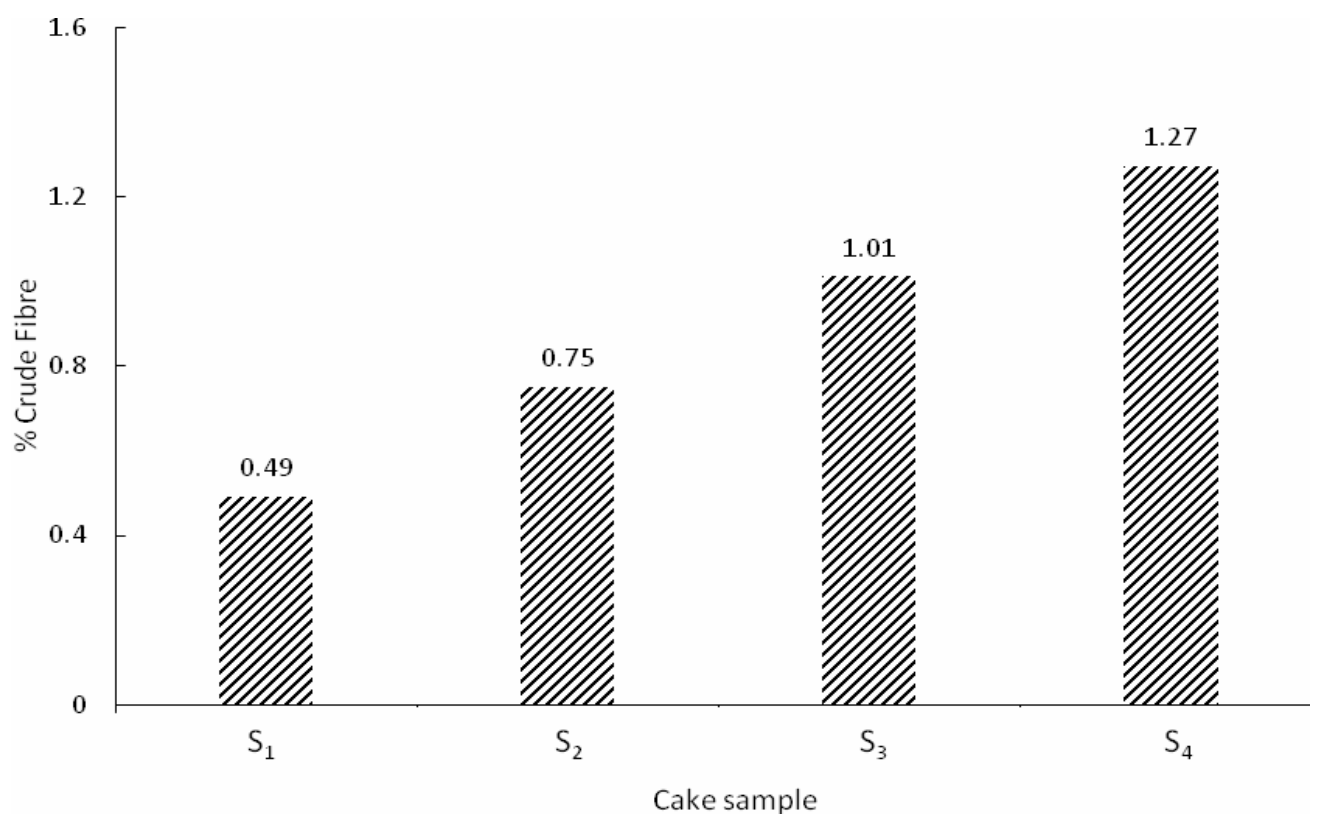

Fig. 7. Crude fibre contents of different cake samples

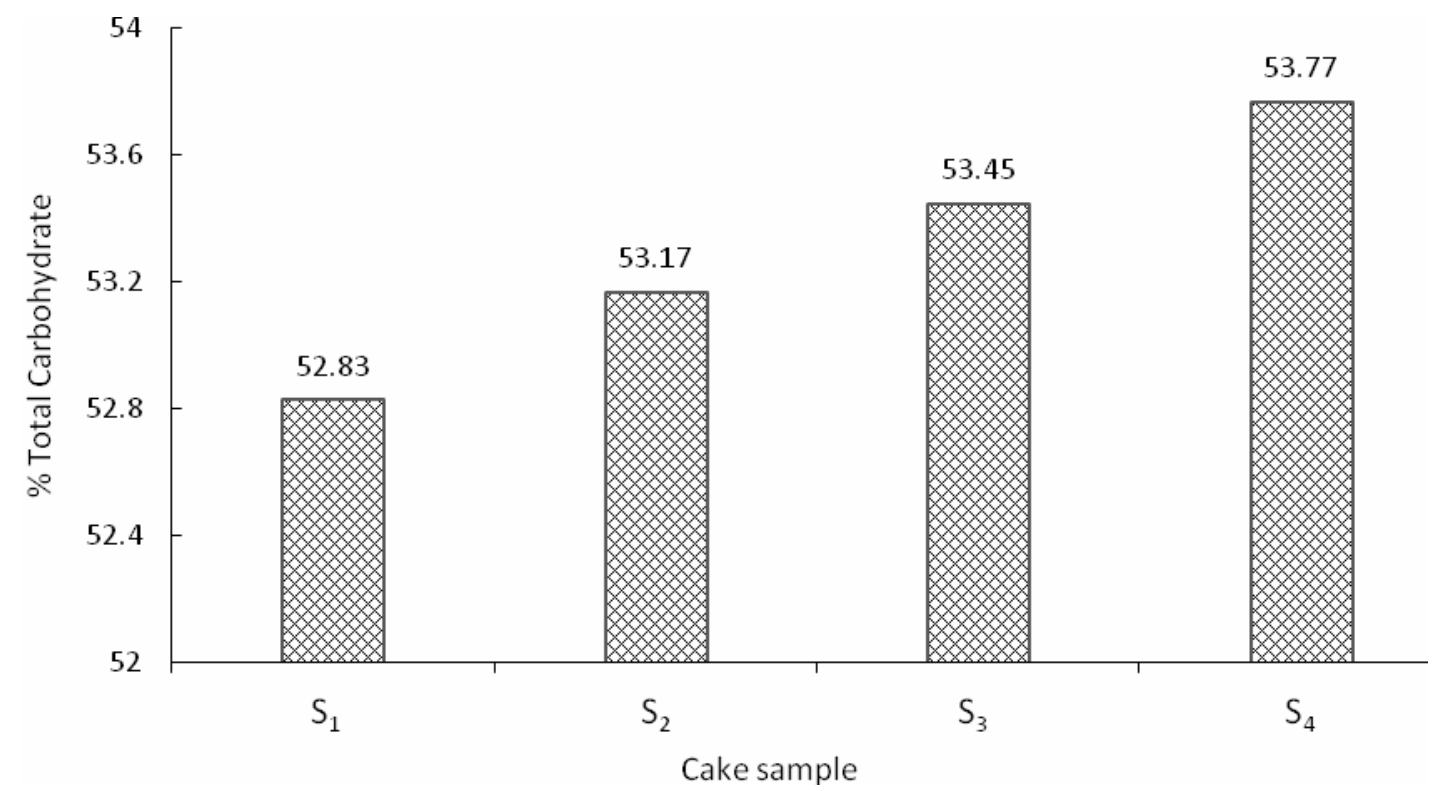

Fig. 8. Total carbohydrate contents of different cake samples

\section{Sensory evaluation}

The statistically analyzed results of sensory evolution is given in Table 4 . The results revealed the acceptance of incorporation of jackfruit seed flour. The finding indicates that the colour of cake sample $\mathrm{S}_{2}$ was more acceptable than other samples. Fig. 9 gives more clear comparison of the cakes. In terms of flavour, sample $S_{1}$ and $S_{2}$ were equally acceptable. As the jackfruit seed incorporation got higher, it gave a lower acceptance. The texture of the samples was not equally acceptable. The sensory panelists gave more preference on sample $S_{1}$ and $S_{2}$ than the other two. The DMRT test for overall acceptability revealed that cake sample $S_{2}$ secured the highest score and equally acceptable with $S_{1}$ whereas while cake sample $\mathrm{S}_{4}(30 \%$ jackfruit seed flour) obtained the lowest among the cakes. 
Table 4. Mean sensory scores of control cake and the cakes containing jackfruit seed flour

\begin{tabular}{ccccc}
\hline Cake type & Color & Flavour & Texture & Overall acceptability \\
\hline${ }^{*} \mathbf{S}_{1}$ & $8.00^{\mathrm{a}}$ & $7.75^{\mathrm{a}}$ & $7.80^{\mathrm{a}}$ & $7.85^{\mathrm{a}}$ \\
$\mathbf{S}_{\mathbf{2}}$ & $8.05^{\mathrm{a}}$ & $7.90^{\mathrm{a}}$ & $7.95^{\mathrm{a}}$ & $8.00^{\mathrm{a}}$ \\
$\mathbf{S}_{\mathbf{3}}$ & $7.30^{\mathrm{b}}$ & $7.55^{\mathrm{a}}$ & $7.00^{\mathrm{b}}$ & $6.95^{\mathrm{b}}$ \\
$\mathbf{S}_{4}$ & $6.35^{\mathrm{c}}$ & $6.55^{\mathrm{b}}$ & $6.20^{\mathrm{c}}$ & $6.15^{\mathrm{c}}$ \\
\hline $\mathrm{CV}(\%)$ & 8.77 & 11.81 & 9.71 & 8.64 \\
LSD & 0.412 & 0.556 & 0.445 & 0.396 \\
\hline
\end{tabular}

${ }^{*} \mathrm{~S}_{1}=$ Control cake (with only wheat flour), $\mathrm{S}_{2}=10 \%$ JSF containing cake, $\mathrm{S}_{3}=20 \%$, JSF containing cake, $\mathrm{S}_{4}=30 \%$ JSF containing cake

Means with different superscripts within a column are significantly different and the same superscripts do not significantly different at $p<0.05$

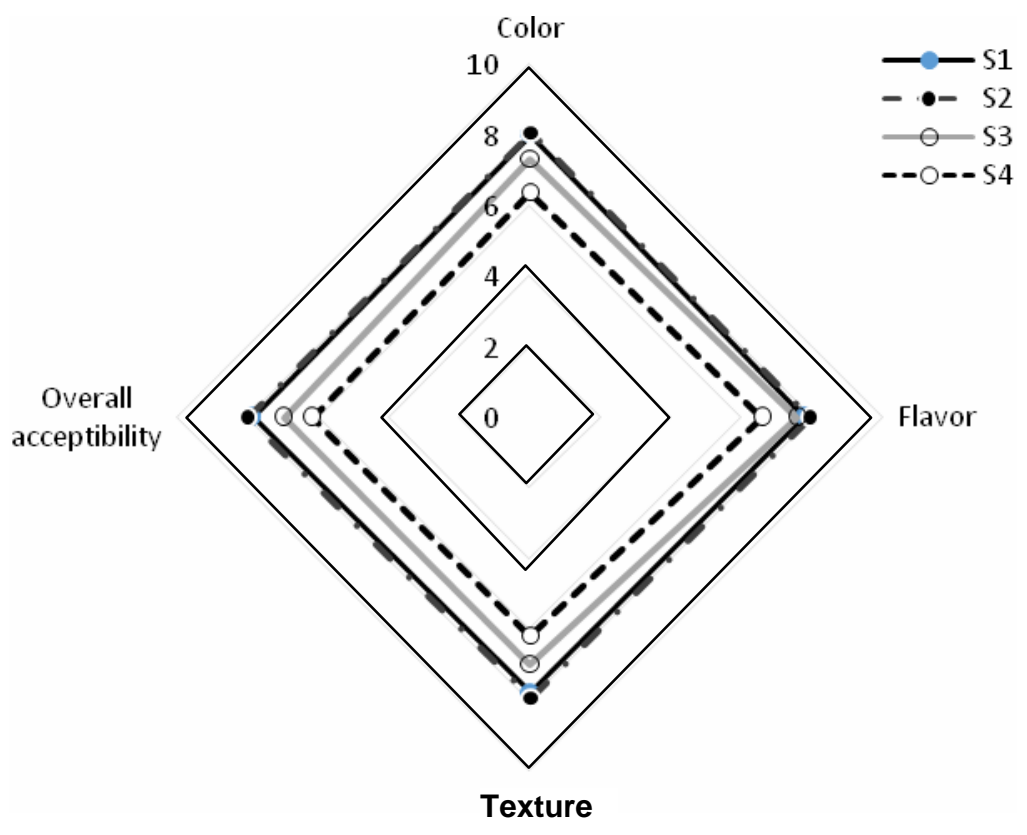

Fig. 9. Spider web plot on sensory attribute profiling of cake incorporation with jackfruit seed flour

\section{Conclusion}

As the knowledge of health, nutrition and diet is diffusing among the general people, the demand of nutritionally enrich food products are increasing at a very high rate. It is more convenient to modify the existing products with locally available raw materials to add some additional attributes without changing sensory parameters. This work recommends JSF as a potential substitute for nutritionally enrich baked products. Further studies may include detailed analysis of nutritional constituents and functional properties of jackfruit seed flour cake.

\section{References}

Amin, M.F.S. 2009. Optimization of jackfruit seed (Artocarpus heterophyllus LAM.) flour and polydextrose content in the formulation of reduced calori chocolate cake. MS Thesis. Department of food technology, Universiti Sains Malaysia.

AOAC. 2012. Official Methods of Analysis., Association of Official Analytical Chemists. $19^{\text {th }}$ Ed., Washington D. C.

Burkil, H.M. 1997. The Useful Plants of West Tropical Africa. Vol.4. 2nd Ed., Royal Botanic Gardens, Kew. pp. 160-161.

Dikeman, C.L., Murphy, M.R. and Fahey, G.C. 2006. Dietary fibers affect viscosity of solutions and simulated human gastric and small intestinal digesta. J. Nutr. 136: 913-919. 
Khan et al.

Kamaljit, K., Baljeet, S. and Amarjeet, K. 2010. Preparation of bakery products by incorporating pea flour as a functional ingredient. Am. J. Food Technol. 5:130-135.

Kunzek, H., Muller, S., Vetter, S. and Godeck, R. 2002. The significance of physico-chemical properties of plant cell wall materials for the development of innovative food products. Eur. Food Res. Technol. 214: 361-376.

Leung, W.T.W, Ritva, R.B., and Fiora, B.S. 1972. Food composition table for use in East Asia. Food and Agriculture Organization of the United Nations, Food Policy and Nutrition Division.

Mollik, M. 2006. Processing and preservation of chapattis from wholemeal flour. MS Thesis, Department of Food Technology and Rural Industries, Bangladesh Agricultural University, Mymensingh.

Ocloo, F.C.K., Bansa, D., Boatin, R., Adom, T. and Agbemavor, W.S. 2010. Physico-chemical, functional and pasting characteristics of flour produced from jackfruits (Artocarpus heterophyllus) seeds. Agriculture and Biology J. of North America, 1(5): 903-908.

Pearson, D. 1976. The Dictionary of Nutrition and Food Technology. 5th Ed., Butterwarthpublication, London.

Pomeranz, Y. 1980. What? How Much? What function? In: bread making. Cereal Food World, 25:656-662.

Rahman, M.A., Nahar, N., Mian, A.J. and Moshiuzzaman, M. 1999. Variation of carbohydrate composition of two forms of fruit from jack tree (Artocarpus heterophyllus Linn.) with maturity and climatic conditions. Food Chem. 65: 91-97.

Rajchel, C.L., Zabik, M.E., Everson, E. 1975. Wheat bran and middlings: A source of dietary fiber in banana, chocolate and spices cakes. Bakers Digest. 49:27-30.

Ranganna, S. 2005. Hand Book of Analysis of Quality Control for Fruit and Vegetable Products. 2nd Ed., Tata McGraw Hill Publication Co. Ltd., New Delhi. pp. 1-30.

SAS. 1985. SAS users guide: Statistics, Version 5th edition. SAS Institute Inc., Cary, NC.

Singh, G., Sehgal, S. and Kawatra, A. 2006. Sensory and nutritional evaluation of cake developed from balanced and malted pearl millet. J. Food. Sci. Technol., 43(5):505-508.

Singh, N., Jha, A., Chaudhary, A. and Upadhyay, A. 2014. Enhancement of the functionality of bread by incorporation of Shatavari (Asparagus racemosus). J. Food Sci. Technol., 51(9):2038-2045.

Upadhyay, A., Sharma H.K. and Sarkar B.C. 2008. Characterization and dehydration kinetics ofcarrot pomace. AgricEng Int., 10: 1-9.

Vassallo, M., Saba, A., Arvola, A., Dean, M., Messina, F., Winkelmann, M., Claupein, E., Lahteenmaki, L. and Shepherd, R. 2009. Willingness to use functional breads: applying the health belief model across four European countries. Appetite, 52: 452-460. 